\title{
CARACTERIZAÇÃO DOS CRITÉRIOS TÉCNICOS PARA SELEÇÃO DE MOTOSSERRAS E ELETROSSERRAS
}

\author{
Catize Brandelero $^{1}$, Valmir Werner ${ }^{1}$, Marcelo Alberto Hilgert ${ }^{2}$, Jaqueline Ottonelli ${ }^{2}$, Bruno Bortoluzzi Benetti ${ }^{3}$, Eliana Andreia \\ Vogt $^{2}$, Tiago Rodrigo Francetto ${ }^{4}$, Airton dos Santos Alonço ${ }^{2}$ \\ 1 Departamento de Engenharia Rural/UFSM, CEP 97105-900, Santa Maria, RS, Brasil. \\ 2 Centro de Ciências Rurais, CCR/UFSM, CEP 97105-900, Santa Maria, RS, Brasil. \\ 3 Curso de Engenharia Florestal, Universidade Federal de Santa Maria, 97105-900, Santa Maria, Brasil. \\ ${ }^{4}$ Coordenadoria Acadêmica/UFSM - Campus Cachoeira do Sul, CEP: 96506-322, Cachoeira do Sul, RS, Brasil.
}

*E-mail: laboratoriomecaniza@gmail.com

\section{RESUMO}

As motosserras e eletrosserras são intensamente utilizadas para o corte de árvores por pequenos produtores rurais, assim como por grandes empresas reflorestadoras. O objetivo deste trabalho é caracterizar os critérios técnicos para a seleção de motosserras e eletrosserras comercializadas no mercado brasileiro. Para isso, os dados foram coletados em catálogos técnicos publicados pelas empresas fabricantes e montadoras dessas máquinas no Brasil. As características analisadas foram: marca, modelo, potência, massa, conjunto motor e de corte. Para a classificação das motosserras e das eletrosserras adotou-se a literatura clássica, em que são diferenciadas como leves, médias e pesadas, adaptando-se as classes de potência conforme modelos disponíveis. Os resultados identificaram 14 marcas de motosserras que produzem 155 modelos com motores de combustão interna (dois tempos). Os resultados para as eletrosserras indicaram a existência de nove marcas que disponibilizam 44 modelos com alimentação de energia por cabos ou baterias. Nas máquinas de uso profissional, a potência varia de 2,30 a $5,20 \mathrm{~kW}$. Nas máquinas para o uso ocasional, as potências normalmente são inferiores a $2,20 \mathrm{~kW}$. As classes média e pesada apresentaram menores relações massa/potência, quando comparadas à classe leve. Verificou-se que com o aumento da potência aumenta-se também a capacidade volumétrica do tanque de combustível. Como critérios para a seleção das máquinas estudadas, destaca-se a finalidade de uso, a relação massa/potência, o volume do tanque de combustível e o comprimento do sabre.

Palavras-chave: Motor dois tempos. Potência. Corte semimecanizado.

\section{Introdução}

A motosserra é uma das máquinas que mais influenciou na mecanização da colheita florestal, substituindo o machado e a serra manual nas operações de derrubada, desgalhamento, traçamento e destopamento de madeira [1]. Assim, quando o corte florestal for realizado com motosserras ou com eletrosserras, denomina-se semimecanizado.

Destaca-se que, entre os anos de 1980 a 1990, a operação de derrubada e de processamento de florestas teve a participação intensiva dessas máquinas. Porém, atualmente, as motosserras são empregadas em áreas onde a colheita florestal mecanizada não pode atuar. Como exemplo, em áreas de inclinação acentuada ou em áreas de preservação permanente (APP's), em que é autorizado o corte de espécies invasoras ou espécies que foram implantadas de forma irregular. Sant'Anna [2] estimou que existam mais de 400.000 motosserras em atividade no Brasil, de diversas marcas, modelos e tamanhos.

Atualmente, com relação à nomenclatura utilizada pelos fabricantes em seus manuais, as motosserras e as eletrosserras estão categorizadas quanto ao uso, podendo ser: ocasional, doméstico, agropecuário, rural, florestal, podas, versátil, multiuso, jardinagem, elétrica, bateria, semiprofissional e/ou profissional. Destaca-se que não existe uma nomenclatura padronizada no país, assim como uma classificação.

Ao buscar no mercado esses tipos de máquinas, é possível encontrar, além de motosserras de motores de combustão interna, 
as eletrosserras com cabo de energia e as alimentadas com baterias. Normalmente, as alimentadas por energia elétrica não são recomendadas para uso profissional nas operações de derrubada de árvores, pois isso pode aumentar os riscos de acidentes, quando na operação do corte de abate de árvores, ao vir faltar energia. Ademais, existe a dificuldade e o risco de manusear cabos elétricos em ambientes abertos, úmidos e com obstáculos. Corroborando com isso, Haselgruber \& Grieffenhagen [3] afirmam que as eletrosserras possuem uso limitado no campo, pois, na maioria dos casos, não existe energia elétrica disponível.

Segundo Linares et al. [4], as serras de uso doméstico/ocasional possuem motores elétricos, com baixa potência e custo de aquisição reduzido. Logo, não são indicadas para a realização de trabalhos que demandam de potência elevada.

Além disso, as motosserras de uso ocasional são máquinas com menor volume deslocado (cilindrada), projetadas para trabalhos leves e de curta duração. São ideais para operação de podas de árvores e arbustos, seccionamento e derrubada de árvores com diâmetros pequenos, bem como, podem ser utilizadas para realizar manutenções em áreas rurais [5]. Já quando a seleção é realizada para uso profissional, um dos principais indicadores para a escolha dessas máquinas é o volume individual por árvore.

As motosserras são máquinas com projetos simples. Segundo Streit et al. [6], são formadas basicamente por dois conjuntos: motor e corte. De acordo com os autores, as motosserras com motores de combustão interna são de dois tempos com carburador ou injeção eletrônica. O motor dois tempos possui esse nome, pois, para cada ciclo do motor, são executadas quatro fases em dois movimentos de $180^{\circ}$ no virabrequim. Nos primeiros $180^{\circ}$, acontece a compressão da mistura de ar e de combustível e, também, a admissão. $\mathrm{Na}$ sequência, ocorre a explosão e o escape, totalizando $360^{\circ}$, reiniciando-se o processo (Figura 1).
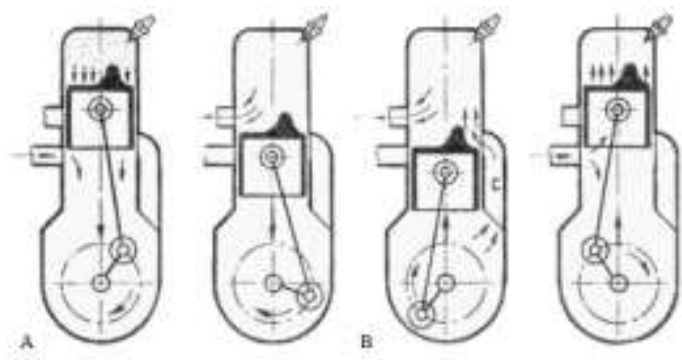

Figura 1 - Funcionamento do motor de ciclo Otto 2 tempos: primeiro tempo (A) e segundo tempo (B) [7].
Esse motor não possui válvulas para gerenciar a entrada e a saída de gases. Essas ações são realizadas pelo próprio movimento do pistão. A admissão e a condução dos gases são realizadas através de aberturas, chamadas de janelas, localizadas no próprio cilindro [6]. Os motores de dois tempos não possuem reservatório de óleo lubrificante, sendo sua lubrificação realizada por emulsão. Isso possibilita que o motor seja leve e trabalhe em diferentes posições (horizontal ou vertical).

O conjunto de corte é formado por embreagem centrífuga, pinhão, sabre e corrente, referenciado por Streit et al. [6], também citado por [8 - 9].

A corrente é formada por dente de corte direito, elo de tração, rebite e dente de corte esquerdo. Nas correntes para uso em motosserras, pode haver variação dos tipos de dentes, calibre e passo. Os dentes das correntes podem ser: quadrados, semiquadrados e redondos (Figura 2).
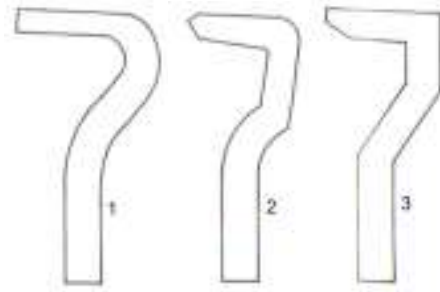

Figura 2 - Vista frontal dos tipos de dentes utilizados em correntes de motosserras e de eletrosserras: redondo (1); semiquadrado (2) e quadrado (3) [6$9,10]$.

Os sabres são fabricados inteiriços. Devido ao esforço a que este é submetido nas operações de corte, normalmente é fabricado em aço, o que proporciona maior resistência a esse componente. $\mathrm{Na}$ extremidade de corte, apresentam blindagem de metal de alta resistência, ponta rolante ou reversora ou, ainda, estrela reversora (Figura 3).
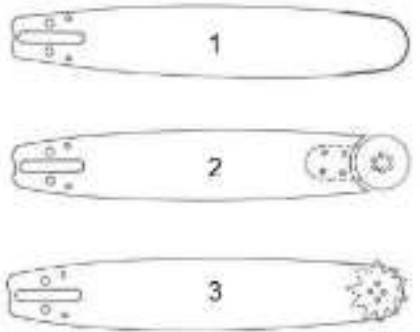

Figura 3 - Tipos de pontas de sabres: inteiriço com blindagem de metal (1); com ponta rolante ou reversora (2) e com roldana reversora ou ponta estrela (3) [6].

O pinhão é o responsável por movimentar a corrente. Atualmente, existem disponíveis no mercado dois tipos de pinhão, um com estrela e outro com tambor e coroa (Figura 4). 


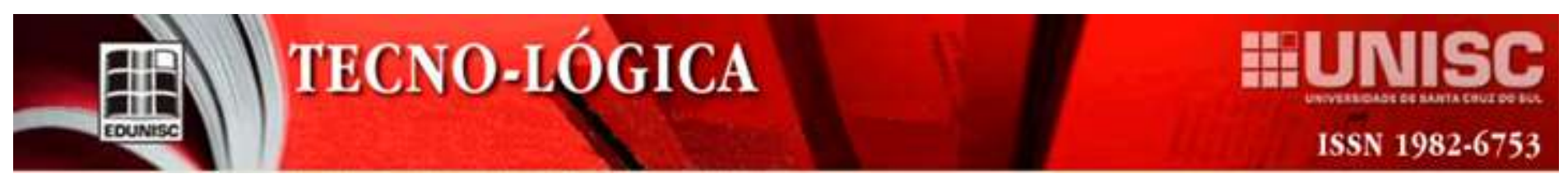

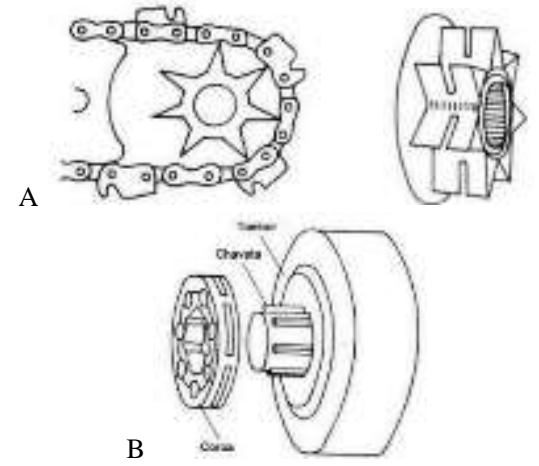

Figura 4 - Tipos de pinhão: com estrela (A) e com tambor e coroa (B) [6 - 10].

As embreagens das motosserras são de acionamento centrífugo. Ao aumentar a rotação do motor, os pesos centrífugos da embreagem são projetados de forma a afastar-se do centro do eixo, acoplando ao tambor que, por sua vez, está interligado ao pinhão, fazendo o acionamento da corrente através dos elos de tração.

Nas eletrosserras, os motores de combustão interna são substituídos por motores elétricos, os quais normalmente apresentam dispositivo protetor eletrônico contra sobrecarga, que mede a temperatura do motor e o consumo de energia. Este poderá interromper a alimentação de corrente elétrica e a máquina será desligada automaticamente [11].

As eletrosserras vêm ganhando representação no mercado brasileiro. A sua praticidade é um item a ser considerado, devido ao fato de pesarem em média $4,5 \mathrm{~kg}$, sendo máquinas de fácil manuseio. A operação é facilitada por não necessitar da realização da mistura de combustível e óleo dois tempos, da regulagem do carburador, entre outros. Essas máquinas são projetadas para atividades leves, que englobem podas de árvores, corte de pequenas toras para lenha e derrubada de árvores com diâmetros de até $30 \mathrm{~cm}$.

Em função das diversas marcas e modelos de motosserras e de eletrosserras disponíveis no mercado brasileiro, faz-se necessário utilizar critérios para a seleção dessas máquinas. Para obter o máximo rendimento operacional, é de suma importância fazer a escolha do modelo adequado à atividade a ser realizada [3]. Na aquisição de tratores agrícolas, são considerados alguns critérios, entre eles, os custos e as especificações técnicas [12]. Entretanto, para as motosserras e eletrosserras disponíveis no mercado, não há critérios técnicos normatizados para a seleção. Conta-se com a classificação clássica de Haselgruber \& Grieffenhagen [3] que compreende somente as motosserras.

Devido ao intenso uso das motosserras e das eletrosserras em pequenas áreas rurais, assim como por grandes empresas reflorestadoras, buscou-se neste trabalho caracterizar os critérios técnicos para a seleção dessas máquinas, com motores de combustão interna e elétricos, comercializadas no mercado brasileiro.

\section{Metodologia}

A coleta de dados foi realizada por meio de pesquisa nos catálogos técnicos disponibilizados pelas empresas fornecedoras de eletrosserras e de motosserras no Brasil, no primeiro semestre de 2018. As informações foram tabuladas em planilha eletrônica utilizando o software Microsoft Excel®. As características analisadas foram: marca, modelo, potência $(\mathrm{kW})$, massa $(\mathrm{kg})$, conjunto motor [rotação máxima (rpm) e capacidade do tanque de combustível (L)], e conjunto de corte [modelo de sabre e comprimento de sabre (m)]. Nenhuma das marcas disponibilizou, na sua totalidade, as informações técnicas para esta pesquisa, bem como não foi encontrada a autonomia de trabalho das eletrosserras.

Mediante a grande quantidade de modelos dessas máquinas disponíveis no mercado, foi adotada a classificação clássica de Haselgruber \& Grieffenhagen [3], em que os autores as categorizam como motosserras leves, médias e pesadas. A categoria leve foi descrita como máquinas com motores de até 40 $\mathrm{cm}^{3}$ e potência de até $2 \mathrm{~kW}$; a categoria média foi descrita com motores de até $60 \mathrm{~cm}^{3}$ e potência de até $4 \mathrm{~kW}$; e a categoria pesada descrita com motores de até $130 \mathrm{~cm}^{3}$ e potência de até 8,5 $\mathrm{kW}$.

No presente estudo, adaptou-se a amplitude das faixas de potência conforme os modelos disponíveis de motosserras e de eletrosserras no mercado brasileiro. As três classes de distribuição de potência definidas foram: leve $(0,7$ a $2,2 \mathrm{~kW})$; média $(2,3$ a $3,7 \mathrm{~kW})$ e pesada $(3,8$ a $5,2 \mathrm{~kW})$. Ainda, foi calculada a relação entre a massa e a potência de cada máquina, onde se obteve o resultado na unidade de medida $(\mathrm{kg} / \mathrm{kW})$.

Para auxiliar na compreensão dos critérios de seleção de motosserras e eletrosserras, foi estruturado o fluxograma com as variáveis consideradas nesta pesquisa (Figura 5).

Compilando os dados e correlacionando-os, foi possível caracterizar os critérios técnicos para auxiliar a seleção de motosserras e eletrosserras. 


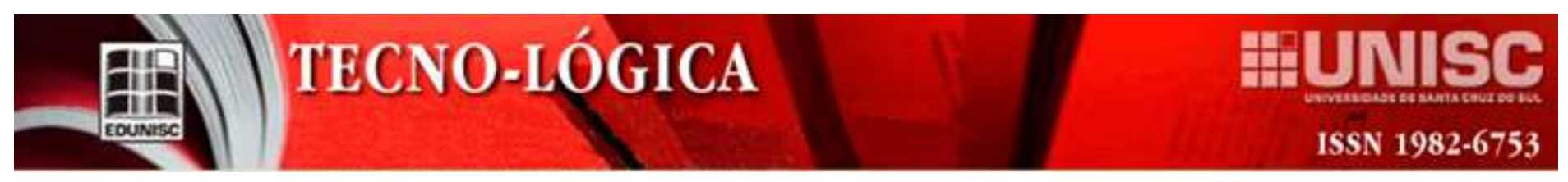

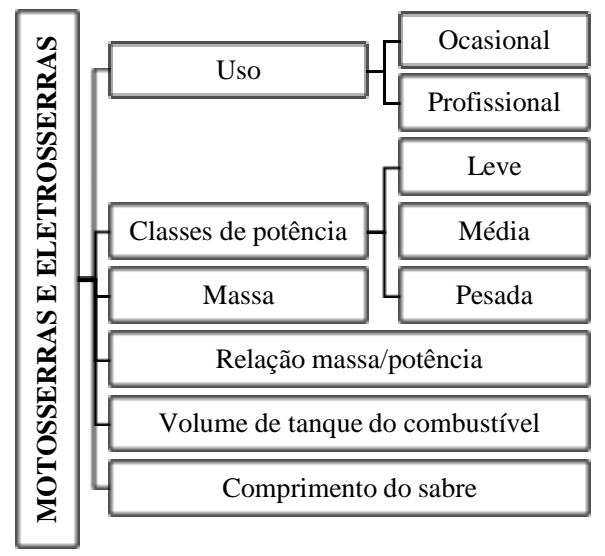

Figura 5 - Fluxograma com os critérios considerados para a seleção de motosserras e eletrosserras.

\section{Resultados e discussão}

Após a realização do levantamento e a análise das informações, foram identificadas 14 marcas de motosserras no mercado brasileiro. Estas comercializam 155 modelos, com motores de combustão interna de dois tempos (Tabela 1). A marca "O" possui o maior número de modelos disponibilizados no mercado nacional, totalizando 29 modelos $(18,70 \%)$ em relação aos demais encontrados na pesquisa. Já a marca "M", conta com 23 modelos $(14,83 \%)$, seguida das marcas "D" e "F", com 18 modelos cada $(11,61 \%)$. As demais marcas, de menor expressão, totalizam $43,25 \%$.

Tabela 1 - Número de modelos de motosserras e de eletrosserras disponíveis no mercado brasileiro.

\begin{tabular}{|c|c|c|}
\hline \multirow{2}{*}{ Marcas } & Motosserras & Eletrosserras \\
\hline & \multicolumn{2}{|c|}{ Número de modelos } \\
\hline $\mathbf{A}$ & 10 & 0 \\
\hline B & 4 & 0 \\
\hline C & 4 & 0 \\
\hline D & 18 & 0 \\
\hline $\mathbf{E}$ & 6 & 2 \\
\hline $\mathbf{F}$ & 18 & 2 \\
\hline G & 4 & 3 \\
\hline $\mathbf{H}$ & 14 & 9 \\
\hline I & 3 & 0 \\
\hline $\mathbf{J}$ & 9 & 2 \\
\hline $\mathbf{K}$ & 5 & 1 \\
\hline $\mathbf{L}$ & 0 & 3 \\
\hline $\mathbf{M}$ & 23 & 18 \\
\hline $\mathbf{N}$ & 8 & 4 \\
\hline $\mathbf{O}$ & 29 & 0 \\
\hline Total & 155 & 44 \\
\hline
\end{tabular}

Das 14 marcas que fabricam motosserras, apenas nove produzem eletrosserras. Estas constituem uma parcela de 22,11\% do mercado, com total de 44 modelos. A marca "M" possui 18 modelos, seguido pela " $\mathrm{H}$ " com nove e a "N" com quatro, representando $40,90 \%, 20,45 \%$ e $9,09 \%$ do mercado, respectivamente.

A distribuição dos modelos por classes está apresentada na Tabela 2. Nas eletrosserras, 16 modelos não foram classificados, devido a essa informação não estar disponível nos manuais dos fabricantes.

Tabela 2 - Modelos de motosserras e de eletrosserras distribuídos em classes.

\begin{tabular}{|c|c|c|c|c|}
\hline \multirow{2}{*}{ Classes } & \multicolumn{2}{|c|}{ Motosserras } & \multicolumn{2}{|c|}{ Eletrosserras } \\
\hline & $\mathrm{N}^{\circ}$ & $\%$ & $\mathrm{~N}^{\circ}$ & $\%$ \\
\hline Leve & 55 & 52,38 & 26 & 92,85 \\
\hline Média & 35 & 33,33 & 2 & 7,15 \\
\hline Pesada & 15 & 14,29 & 0 & 0,00 \\
\hline Total & $105^{*}$ & 100 & $28^{*}$ & 100 \\
\hline
\end{tabular}

Existe uma concentração de modelos na classe leve, que agrupa os modelos destinados ao uso doméstico e/ou ocasional. Isso se deve ao fato do usuário dessa classe realizar diversas atividades de baixo impacto e de forma eventual, como podas, abate de árvores de pequeno porte (sub-bosque) e seccionamento de toras de pequeno diâmetro. Por outro lado, a classe com menor quantidade de modelos é a pesada, que agrupa as máquinas de uso profissional, adequadas para corte em áreas de produção florestal, na colheita semimecanizada que visa a produtividade. De acordo com Haselgruber \& Grieffenhagen [3], o rendimento está relacionado à escolha adequada da motosserra, o que na prática nem sempre é possível. Os autores afirmam que a escolha de uma motosserra, que se adapte a qualquer atividade, deve considerar as condições de densidade da madeira, assim como a idade e as condições do povoamento.

Além disso, as motosserras de uso profissional apresentam maior volume deslocado e potência. São máquinas normalmente mais pesadas que podem ser operadas em condições severas, onde o acesso por máquinas especializadas é limitado [13 - 14].

Na Tabela 3, são apresentadas as massas mínimas, médias e máximas, e a relação massa/potência para cada classe de potência de motosserras.

Tabela 3 - Distribuição de massa das motosserras e a relação massa/potência.

\begin{tabular}{ccccccc}
\hline \multirow{2}{*}{ Classes } & \multicolumn{3}{c}{ Massa (kg) } & \multicolumn{3}{c}{ Relação massa/potência (kg/kW) } \\
\cline { 2 - 7 } & Mín. & Méd. & Máx. & Mín. & Méd. & Máx. \\
\hline Leve & 2,50 & 5,01 & 7,80 & 2,04 & 2,63 & 6,25 \\
\hline Média & 4,60 & 6,46 & 8,80 & 1,65 & 2,63 & 3,30 \\
\hline Pesada & 6,20 & 7,22 & 8,40 & 1,37 & 1,62 & 1,91 \\
\hline
\end{tabular}

Observa-se que na primeira classe existem motosserras com disparidade de massa, variando com amplitude de 5,3 kg. Isso se deve à grande quantidade de modelos disponíveis no 
mercado e à ausência de normas que restrinjam a fabricação de máquinas com essa relação. Já na classe média, os valores de massa variam em uma amplitude de $4,20 \mathrm{~kg}$, apontando redução da amplitude de massa. Observa-se na classe pesada a redução da amplitude de massa para apenas $2,20 \mathrm{~kg}$. Constata-se que na classe leve existem modelos com massas mais elevadas do que modelos pertencentes às classes média e pesada. Márquez [15] salienta que a massa de uma máquina agrícola influencia diretamente no desempenho a campo desta.

Com relação ao fator massa/potência, as classes leve e média apresentam valor médio de $2,63 \mathrm{~kg} / \mathrm{kW}$, o que expressa que na classe leve existem máquinas com massa elevada e potência baixa. Já na classe pesada, essa relação média é de apenas $1,62 \mathrm{~kg} / \mathrm{kW}$, o que caracteriza máquinas relativamente leves e com potência elevada. Assim, ao analisar a relação massa/potência com a busca por um maior rendimento operacional (metro cúbico/operário/hora efetiva), é de suma importância, na hora da aquisição dessa máquina, optar por modelos que possuam relação massa/potência baixa. Corrobora com a análise Márquez [15] ao indicar que, no processo de seleção, deve-se optar por modelos com a menor relação massa/potência e que seja compatível com o tipo de operação a ser efetuada.

Isso porque a massa da motosserra pode influenciar diretamente no rendimento da operação. Para Torrijos et al. [16], a motosserra é uma máquina manipulada manualmente, devendo ser o mais leve possível. Por outro lado, quanto mais pesada for a máquina, maior será o esforço físico do operador, bem como a fadiga, o que resultará em um maior número de paradas para descanso. Essas paradas geram redução do tempo efetivo de trabalho e, consequentemente, redução da produção em metros cúbicos por hora efetiva. Em pesquisa conduzida por Borges [17], aplicando ferramentas de análise ergonômica do trabalho com motosserristas, constatou-se que ocorrem lombalgias e desconforto em função do esforço físico acentuado do operador.

Os autores [18 - 19] ressaltam a importância de analisar os fatores de projetos de forma harmônica, pois o conjunto desses parâmetros afeta o desempenho das máquinas agrícolas. Logo, a relação massa/potência é um importante fator a ser considerado.

Outro critério a ser considerado para a seleção dessas máquinas é o volume do tanque de combustível, pois existe variação nos modelos encontrados no mercado brasileiro. A máquina com menor capacidade possui 0,2 litros na classe leve e a de volume máximo apresenta capacidade de 1,0 litro na classe pesada (Tabela 4). A capacidade do tanque de combustível determina a autonomia de trabalho ininterrupto da máquina. Portanto, essa é uma variável importante para as operações a serem conduzidas.
Tabela 4 - Volumetria de tanque de combustível distribuídos nas classes consideradas no estudo.

\begin{tabular}{cccc}
\hline \multirow{2}{*}{ Classes } & \multicolumn{3}{c}{ Capacidade volumétrica de tanque $(\mathbf{L})$} \\
\cline { 2 - 4 } & Mín. & Méd. & Máx. \\
\hline Leve & 0,20 & 0,40 & 0,55 \\
\hline Média & 0,44 & 0,58 & 0,80 \\
\hline Pesada & 0,68 & 0,82 & 1,00 \\
\hline
\end{tabular}

Por outro lado, nas eletrosserras existem limitações quanto ao fornecimento de energia a campo [1 - 3]. Na pesquisa, observou-se que os fabricantes não informam a autonomia das baterias ou a relação de trabalho com o resfriamento dos motores elétricos.

Com relação à motorização das motosserras, um fator importante é a rotação máxima do motor, pois determina a velocidade máxima da corrente. Sendo assim, quanto maior a rotação do motor, maior também será o rendimento da motosserra. No mercado brasileiro, foram encontrados modelos que variam a rotação máxima de trabalho entre 10.000 e 14.000 rotações por minuto $(\mathrm{rpm})$. Cada motosserra possui uma rotação mínima e máxima recomendada pelo fabricante, podendo ser regulada no carburador, com o auxílio de um tacômetro (no volante do motor). Segundo Haselgruber \& Grieffenhagen [3], ao utilizarmos motosserras de menor potência no momento do corte de árvores, a rotação cai significativamente. Dessa maneira, é fundamental exercer menor pressão da máquina sobre o material a ser cortado.

Com base nos dados levantados, constatou-se que os sabres para essas máquinas variam de 0,20 a 0,90 metros de comprimento. Máquinas da classe leve admitem apenas sabres pequenos, pelo fato de serem máquinas com menor potência. Já motosserras médias e pesadas comportam sabres pequenos, médios e grandes. Cabe destacar que o comprimento do sabre tem efeito direto sobre a massa da máquina e, consequentemente, sobre a questão ergonômica no trabalho. É um aspecto importante na escolha da máquina. Para selecionar o sabre adequado, utiliza-se os fatores: diâmetro das árvores a serem colhidas/seccionadas e a densidade da madeira. Corroboram nessa análise Murara Junior et al. [20], ao afirmarem que o rendimento em madeira serrada é influenciado por diversas características, tais como: máquina, mão de obra e, principalmente, diâmetro das toras. Por exemplo, Torrijos et al. [16] ilustram a relação do diâmetro do tronco com o comprimento de sabre a ser utilizado (Figura 6). 
Diâmetro do tronco $(\mathrm{cm})$
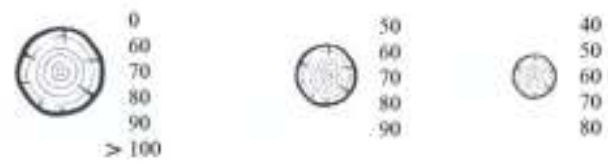

40
50
60
70
80

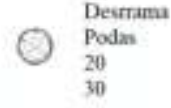

Comprimentro do sabre (cm)
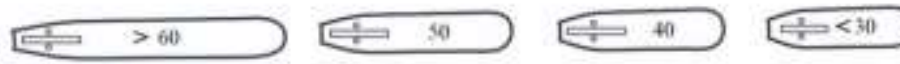

Figura 6 - Comprimento do sabre da motosserra em função do diâmetro das árvores. Adaptado de Torrijos et al. [16].

Segundo Torrijos et al. [16], os sabres devem ser selecionados quanto ao comprimento e a largura. Os autores inferem que, para o desgalhamento, faz-se necessário um sabre curto, exceto para árvores com galhos grossos. Já no seccionamento, podem ser utilizados sabres curtos e estreitos, porém, sempre observando o diâmetro individual da árvore.

\section{Conclusões}

É ampla a oferta de eletrosserras e de motosserras no mercado brasileiro e não há critérios técnicos normatizados para o processo de seleção. Os fabricantes normalmente caracterizam suas máquinas como de uso ocasional ou profissional.

A classificação clássica é estruturada a partir da potência dos motores. A classe leve é a que apresenta maior número de modelos de motosserras e de eletrosserras. Na classe pesada, não existem eletrosserras.

As motosserras da classe pesada apresentam maior massa média total, seguida das classes média e leve. Já na relação massa/potência média, a classe pesada apresenta menor relação quando comparada as classes leve e média. Quanto ao volume de tanque de combustível, este fator é determinante na autonomia de trabalho. Já para as eletrosserras, a autonomia das baterias e a extensão dos cabos.

Motosserras da classe leve não comportam sabres longos. As pertencentes às classes média e pesada comportam sabre curto, médio ou longo.

\section{CHARACTERIZATION TECHNICAL CRITERIA FOR SELECTION OF CHAINSAWS AND ELETRIC SAWS}

ABSTRACT: Chainsaws and electric saws are intensively used for cutting trees by small farmers as well as by large reforestation companies. This study aims to characterize the technical criteria for the selection of chainsaws and electric saws commercialized in the Brazilian market. Data were gathered from technical catalogs published by manufacturing companies and assemblers of these machines in Brazil. We analyzed the following characteristics: brand, model, power, mass, motor, and cutting assembly. For the classification of chainsaws and electric saws in technical criteria, we adopted the classical literature that differentiate the machines as light, medium and heavy. We adopting the power classes according to the available models. Results identified 14 brands of chainsaws that produce 155 models with internal combustion engines (two-stroke). Results for electric saws indicate the existence of nine brands that offer 44 models with power supply by cables or batteries. In professional machines, power ranges from 2.30 to $5.20 \mathrm{~kW}$. In machines for occasional use, power is usually less than $2.20 \mathrm{~kW}$. The middle and heavy classes had lower mass/power ratios when compared to the light class. We found that the increase in power also increases the volumetric capacity of the fuel tank. As criteria for the selection of studied machines, we highlight the purpose of use, mass/power ratio, fuel tank volume and saber length.

Keywords: Two-strokes engine. Power. Semi-mechanized cut.

\section{Referências}

[1] LOPES, E. S.; MINETTE, L. J. Operação e manutenção de motosserras: manual técnico. Viçosa, MG: Aprenda Fácil, 2001. 152 p.

[2] SANT'ANNA, C. M. Corte. In: MACHADO, C. C. Colheita florestal. 3. ed. Viçosa, MG: UFV, 2014. p. 74-105.

[3] HASELGRUBER, F.; GRIEFFENHAGEN, K. F. G. Motosserras, mecânica e uso. Porto Alegre: Metrópole, 1989. 136 p.

[4] LINARES, V.G.G.; et al. Manual de mecanización de los aprovechamientos forestales. Madrid: Ediciones Mundi - Prensa, 2014. 374 p. ISBN: 9788484766414.

[5] OTTONELLI, J. Caracterização do uso e estado de conservação de motosserras de ciclo Otto 2 tempos. 2017. 72 p. Dissertação (Programa de PósGraduação em Engenharia Agrícola - Mestrado) - Universidade Federal de Santa Maria, Santa Maria, 2017.

[6] STREIT, M.; OLIVEIRA, M. S. M.; HASELGRUBER, F. Mecanização florestal. In: NAGY, J. L. (Coord). Manual do técnico florestal; apostilas do Colégio Florestal de Irati. Campo Largo, Ingra S.A., Vol. 2, 479 p, 1986.

[7] MIALHE, L. G. Máquinas motoras na agricultura. São Paulo: EPU: Ed. Da Universidade de São Paulo, Vol. 1, 290 p, 1980.

[8] ROBERT, R. C. G. Guia prático de operações florestais na colheita de madeira. Curitiba: Ed. do autor, 2012. 112 p. 
[9] VERLAG EUROPA-LEHRNITTEL. Fachkunde Land-und Baumaschinentechnik. Haan-Gruiten. 832 p, 2016 ISBN: 978-3-885-2007-9.

[10] OREGON, B. Manual de Mantenimiento y Seguridad. Portland, EUA, 2004. $104 \mathrm{p}$.

[11] STIHL. Manual de instruções de serviços - MSE 170 C, MSE 190 C, MSE 210 C, MSE 230 C. SÃO LEOPOLDO-RS. 52 p. Disponível em: <https://www.stihl.com.br/manuais-de-instrucoes.aspx?spm=MS\&Search=>. Acesso em: 28 de maio de 2018.

[12] SCHLOSSER, J. F. Critérios de seleção de máquinas agrícolas - Parte II. Cultivar (Pelotas), Pelotas, Vol. II, n.18, p. 18-21, 2003.

[13] SANT'ANNA, C. M. Corte florestal. In: Machado, C.C. (Ed). Colheita florestal, Viçosa, Minas Gerais, 2002. p. 55-88.

[14] SANT'ANA C. M.; MALINOVSKI, J.R. Análise de fatores humanos e condições de trabalho de operadores de motosserra de minas gerais. Cerne, Vol. 8, n.1, p. 115-121, 2002.

[15] MÁRQUEZ, L. Solo Tractor '90. Madrid: Laboreo, Apuntes didácticos, 1990. $198 \mathrm{p}$.

[16] TORRIJOS, Y.A.; et al. Apeo de árboles con motosierra. Espanha: Ediciones Paraninfo, S.A. 2012. 146 p. ISBN: 978-84-283-3336-8.

[17] BORGES, R. Z. Análise ergonômica do trabalho como ferramenta para a gestão de riscos na colheita florestal. 60 p. Monografia (Especialização em Engenharia de Segurança do Trabalho) - Centro Universitário Franciscano Santa Maria, RS. UNIFRA, 2015.

[18] MARINI, V.K. Fatores de influência e funções técnicas no projeto de máquinas agrícolas: uma contribuição teórica. 2007. 181 p. Dissertação (Mestrado em Engenharia Agrícola) - Universidade Federal de Santa Maria, Santa Maria, RS

[19] CHRISTIANSON, L.L.; ROHRBACH, R.P. Design in agricultural engineering. St. Joseph: ASABE, 1986. 310 p.

[20] MURARA JUNIOR, M. I.; ROCHA, M. P.; TIMOFEICZYK JUNIOR, R. Rendimento em madeira serrada de Pinus taeda para duas metodologias de desdobro. Floresta, Curitiba, Vol. 35, n. 3, set./dez. 2005. 